\title{
Danskernes brug af nyhedsmedier: et nyt landkort En pejling af danskernes navigation i nyhedsuniverset
}

\section{AF KIM SCHRØDER, ROSKILDE UNIVERSITET}

Artiklen fremlægger første del af en analyse, der på en ny måde kortlægger danskernes brug og oplevelse af nyheder i det medialiserede samfund, på tværs af de forskellige - traditionelle og digitale - medieplatforme og genrer. Teoretisk er undersøgelsen forankret i offentlighedsteorien og den begrebsmæssige nyudvikling af teorien i retning af 'kulturelt borgerskab' og 'public connection'. Undersøgelsen operationaliserer denne teoretiske inspiration ved at opstille og diskutere et nyt begreb om mediebrug som betinget af brugerens oplevelse af de forskellige nyhedsmediers relative 'worthwhileness', såvel for demokratisk handling som for evnen til at navigere hensigtsmæssigt i hverdagens mangfoldige gøremål. Empirisk fremlægger artiklen resultaterne af en online-spørgeskemaundersøgelse, der kortlægger borger/forbrugerens færden i dagens nyhedslandskab på tværs af trykte medier, radio, tv og internettet, i forhold til to nyhedsfunktionaliteter: 'overblik' og 'baggrund'. Undersøgelsen finder blandt andet frem til, at netnyheder er ved at nå op på siden af TV-mediet som danskernes foretrukne nyhedsmedier, at Tekst-TV er et væsentligt men hidtil overset nyhedsmedie, og kortlægger desuden de forskellige nyhedsmedier i spændingsfeltet mellem information og underholdning. 
Denne artikel fremlægger første del af en analyse, der på en ny måde kortlægger brug og oplevelse af nyheder, på tværs af de forskellige medieplatforme, der tilbyder danskerne forskellige former for informationer om, hvad der rører sig i samfundet omkring dem. ${ }^{1}$

Analysen går ud fra, at de fleste voksne individer i det danske samfund har et løbende, generelt - men også stærkt differentieret - behov for at holde sig orienteret om, hvad der sker på lokalt, regionalt, nationalt og internationalt plan. Dette generelle behov for informationer manifesterer sig i form af en lang række af mere specifikke behov, som de enkelte individer har, i kraft af „hvem de er“. De forskellige nyhedsmedier kan betragtes som en række muligheder for at opfylde disse forskelligartede behov - som ressourcer, som den enkelte kan trække på for at realisere de bevidste og ubevidste 'projekter', som vi alle lever vores liv med.

Gennem vores livsforløb har vi hver især opbygget os en portfolio af de nyhedsmedier, vi sædvanligvis, eller for tiden, betjener os af, og de indgår i vores hverdagsrutiner, oftest på en selvfølgelig og uplanlagt måde, dér hvor det „passer ind“. Det at følge med i forskellige nyhedsmediers fortællinger om, hvad der sker i verden, er groet ind i vores hverdagsvaner (Berelson 1949). Men vanerne er ikke uforanderlige: Når vores livsomstændigheder ændrer sig, når der dukker et nyt nyhedsmedie op med en ny måde at skrue virkelighedsskildringen sammen på, når nye teknologier tilbyder nye måder at tilegne sig informationer på - så kan der ske ændringer i den mediepalet, vi betjener os af.

Vi skifter én avis ud med en anden; vi afbestiller abonnementet på avisen og begynder at læse nyheder på nettet; vi opdager at kombinationen af Tekst-TV og TV 2 News passer os godt, når vi vil have et hurtigt nyhedsoverblik; vi begynder at køre i bil til og fra arbejde og skifter gratisavisens nyhedsoverblik fra toget ud med $\mathrm{P} 4$ 's radionyheder; vores kabelnet tilbyder en pakke med kanalen BBCWorld og lige så stille begynder vi at se den hver aften i timen inden midnat; eller vi opdager på en rejse, at en kollega henter sportsnyheder på mobiltelefonen, og får selv fat på en mobiltelefon med denne facilitet. Og så videre.

Det er en præmis for denne analyse, at folks valg af nyhedsmedier - den ‘konstellation' af nyhedsmedier (Couldry m.fl. 2007), 
som indgår med en vis stabilitet i deres informations- og oplevelsessøgning - bestemmes af, hvad de bevidst og ubevidst anser for at være deres „umage værd“, dvs. hvad de oplever som en kumulativ opfyldelse af deres erkendte og uerkendte behov for viden om, hvad der sker i verden omkring dem. Folk bruger kun de nyhedsmedier, som de oplever giver dem en eller anden form for „pay-off“ - de skal „have noget ud af“ at bruge de medier de bruger.

Brugen af nyhedsmedier bestemmes altså af deres relative „worthwhileness“ for den enkelte. Den engelske betegnelse anvendes i mangel af et præcist dansk udtryk til at betegne, at et givet nyhedsmedie skal have en form for brugsværdi for den enkelte. Den danske oversættelse af „worthwhile“ (umagen værd“) er ikke et dækkende begreb, fordi det i ordet 'umage' peger i retning af, at brugen koster anstrengelse og indeholder et element af pligt, hvad der kun lejlighedsvis er tilfældet med brugen af nyhedsmedier (sådan som det fx for nogle kan være en form for pligt at læse den daglige avis). ${ }^{2}$

\section{Undersøgelsens baggrund og formål}

Selv om der er lavet nærmest uendelige mængder af undersøgelser af nyhedsmedierne i Danmark og andre lande (fx Hjarvard 1999, Lund 2000 og 2002, McNair 2006, Kabel 2009, Lund m.fl. 2009), så er der stadig nogle sider, der er underbelyst. Det er formålet med denne analyse at tage hul på at belyse nogle af de underbelyste aspekter ved danske nyhedsmediers måde at fungere på i det danske samfund - aspekter der både handler om nyhedsmediernes demokratiske roller og deres generelle indbygning i befolkningens hverdagsliv.

Analysen anlægger et tværmedialt brugerperspektiv på nyhedsudbuddet, hvor det handler om at finde mønstre og logikker i forbruger-borgernes kollektive måder at holde sig informeret på gennem nyhedsmedier. Perspektivet er ikke de forskellige nyhedsmediers og reklamebureauernes brancheforankrede interesser $\mathrm{i}$ at vide noget om brugeradfærd, men samfundets interesse $\mathrm{i}$ at vide noget om, hvordan brugerne finder det meningsfuldt at navigere i nyhedsuniverset. Når vi spørger til deres ny- 
hedsmediepræferencer, så indbygger vi et relationelt perspektiv i undersøgelsen, i og med at vi beder respondenterne om at forholde sig til de forskellige nyhedsmedier i forhold til hinanden. Desuden sætter vi fokus på nyhedsmediernes mulige funktionaliteter i borgernes hverdagsliv, i forhold til et behov for overblik og et behov for baggrundsinformation og dybde. Endelig argumenterer vi for, at det giver mening at forstå disse aspekter ved brugen af nyhedsmedier ved hjælp af den teoretiske optik, der ligger i begrebet 'worthwhileness'. Undersøgelsen udpeger derfor de medier, som det kan være vigtigt at analysere nærmere med henblik på at få viden om, hvad folk konkret bruger dagens dominerende nyhedsmedier til, og hvordan de lader dem indgå i hverdagens øvrige rytmer af arbejds- og fritidsliv.

I næste afsnit præsenteres worthwhileness-begrebet kort, med det formål at fremlægge den teoretiske optik, der ligger til grund for udformningen af undersøgelsen. Denne optik på tværmedial nyhedsmediebrug adskiller sig nemlig fra den brancheforståelsesramme, der er styrende for den nyudviklede tilgang til tværmedial mediebrugsanalyse, der er udviklet af TNS Gallup under navnet MultiMediaMennesket (Kromann-Larsen 2009), og som er inspireret af den Touchpoints-analyse, der er lavet i England af The Institute of Practitioners of Advertising (Beeftink 2009).

Det er formålet med MultiMediaMennesket at tilvejebringe en dybere indsigt i befolkningens medieforbrug på tværs af platforme, for at skabe et multimedia-planlægningsværktøj, der kan ramme forbrugere, når de er mest modtagelige for reklamebudskaber. For at opnå dette mål registrerer man 2000 voksne danskeres aktiviteter og medieforbrug i halvtimes-intervaller gennem 7 dage, så man minutiøst kan kortlægge deres færden i forhold til hvad, hvornår, hvor, med hvem, hvorfor. Til forskel herfra er det formålet med en worthwhileness-tilgang at forstå hvordan menneskers brug og engagement i forskellige (nyheds)medier indgår i og beriger deres liv, og fungerer som ressourcer i de mangfoldige gøremål, folk bevæger sig igennem i hverdagen. For den reklameorienterede tilgang er en instrumentel minutfor-minut viden nødvendig for at man når som helst kan ramme den sårbare forbruger gennem det optimale reklamemedie. For worthwhileness-tilgangen er det vigtige at forstå, hvordan men- 
nesker gør deres medie- og tidsforbrug meningsfulde for dem selv i forhold til dagens og ugens forløb, og i forhold til deres samvær med andre mennesker.

\section{Dimensioner i nyhedsmediers 'worthwhileness'}

\section{Tid}

Det engelske udtryk 'worthwhileness' indeholder den betydning, at brugen af et nyhedsmedie skal "passe ind“ i det liv, man lever i hverdagen: Det skal være den tid værd, som man bruger på det. Og i og med at tiden kan være mere eller mindre kostbar i løbet af en dag, så skal der være forskellige former for „pay-off“ på forskellige tidspunkter af dagen. Visse nyhedsmedier er der kun plads til i tidslommer, hvor man ikke har andet at give sig til, således som det for nogle er tilfældet med gratisaviserne i toget på vej til arbejde. De er således „worthwhile“ i mangel af bedre (,worthwhile by default“).

Andre nyhedsmedier er vigtige at få konsulteret regelmæssigt, og man tager sig tid til at bruge dem, som når man måske udsætter sin sengetid med en halv time for at nå at få læst dagens abonnementsavis, eller en søndag eftermiddag læser de fagblade, som man er kommet bagefter med.

\section{Forbindelse til fællesskabet}

„Worthwhileness“ er en kompleks størrelse, der består af andre dimensioner end tid til at bruge et nyhedsmedie i en given situation. De engelske medieforskere Couldry, Livingstone \& Markham (2007) mener, at det, der i sidste instans er afgørende for, om man bruger et nyhedsmedie, er om det leverer forbindelse til fællesskabet ('public connection'), eller rettere forbindelse til de forskellige fællesskaber, vi hver især tilhører, både i de mellemmenneskelige situationer, vi færdes i i hverdagslivet (i familien, på arbejdspladsen, hvor vi bor, hvor vi dyrker fritidsinteresser, osv.), og i de geografiske, politiske og institutionelle rammer, vi hører til i (vores land, vores region, vores by, vores børns skole, osv.) og som tildeler os nogle roller som aktører i forhold til beslutningsprocesser (hvor vi kan være vælgere og selv blive valgt til poster med forskellige former for beslutningskompetence). 
Der kan skelnes mellem to former for forbindelse til fællesskabet:

1) Demokratisk worthwhileness: Der er en lang tradition (som kan forankres i fx Habermas's teori om offentlighed (Habermas 1962; 2006)) for udelukkende at vurdere vores mediebrug i forhold til rollen som myndig borger, og for at se på i hvilken udstrækning mediernes nyhedsformidling sætter os i stand til at udfylde rollen som kompetent og myndig borger i et deliberativt demokrati (Dahlgren 2001): Giver medierne os den nødvendige viden, som vi skal bruge for at kunne tage stilling til politiske spørgsmål, og fungerer medierne som hensigtsmæssige fora for den politiske debat, som er demokratiets fundament? For mange mennesker afhænger deres valg af nyhedsmedier af, hvor de mener, at de får de bedste ressourcer til rollen som kompetent borger. For dem skal der altså være en høj grad af demokratisk worthwhileness i brugen af et medie, for at det vinder plads i hverdagens tidsforløb. Traditionelt har vægtningen af den demokratiske borgerrolle medført, at de informations- og baggrundstunge medier (især abonnementsaviserne og public service-kanalernes nyhedsformidling) blev anset for finere end andre, mens de mere underholdningsprægede og overfladiske medier er blevet nedvurderet (formiddagsaviser, ugeblade, realityprogrammer og talkshows) (Postman 1985, Bourdieu 1998).

2) Hverdagslivets worthwhileness: I praksis viser det sig imidlertid, at folk også i høj grad - og nogle udelukkende - vælger medier efter, om de leverer de informationsressourcer, som folk har brug for, for at kunne fungere tilfredsstillende som hverdagsmennesker i samspil med andre mennesker i hverdagens mangfoldige sammenhænge. Man kan her tale om en hverdagslivets worthwhileness, hvor det handler om, at medierne leverer det stof, vi skal bruge for helt banalt at kunne navigere i dagligdagen som ægtefælle, kollega, nabo, forbruger og almindeligt menneske: informationer om vejret, trafikken, fødevarer, sundhed, børneopdragelse, tøj, husdyr, ferier, sex, film, sport, om de kendte og de kongelige, osv.

I medieforskningen har man iagttaget den forskydning, der er sket over de seneste årtier i retning af, at flere og flere medier for- 
søger at sælge sig selv til brugerne ved at levere ressourcer til hverdagslivets worthwhileness, ved at forsyne os med forbruger-, service- og sladderstof. Det er resulteret i et overordnet signalement af medierne gående på, at medierne ud over rollen som „fjerde statsmagt“ også har fået rollen som "fjerde servicemagt", hvor samfundsborgerne er blevet afhængige af den førstehjælp medierne leverer, så folk kan få hverdagen til at hænge sammen (Eide 1992).

Samtidig har nogle forskere fremført den pointe, at det ikke er holdbart at skelne skarpt mellem det politisk respektable stof og det suspekte og underlødige underholdende stof (Van Zoonen 2005, Dahlgren 2006, Jones 2006, Delli Carpini \& Williams 2001), fordi den politiske dimension altid er potentielt indbygget i selv de mest banale former for hverdagsstof-hvor fx fødevarer er blevet en kampplads for sundheds- og miljødebatten, og hvor beskæftigelsen med 'de kendte' er blevet til en kontinuerlig pejling og forhandling af, hvordan vi hver især til stadighed 'bygger på' vores identitet og livsstil. Enhver artikel om Naser Khader, eller et talkshow hvor Naser Khader medvirker, handler således også (eksplicit eller implicit) om etnisk identitet i det danske samfund og om udviklinger i det partipolitiske landskab (Bødker 2007).

Det er dokumenteret at vores brug af et nyhedsmedie afhænger af, om vi oplever dets indhold som relevant for os selv (Poulsen 1998). Relevansdimensionen kan ved nærmere betragtning ses som underordnet dimensionen om 'forbindelse til fællesskabet' - fordi det medieindhold, vi oplever som relevant, nødvendigvis vil være indhold der fungerer som katalysator for vores relationer til andre mennesker. Om jeg vælger at læse den ene avis frem for den anden afhænger af, hvilken af dem der bedst sætter mig i stand til at snakke med de mennesker, jeg gerne vil kunne snakke med. Hvis jeg som Politiken-læser gør mig den erfaring, at jeg ved at læse Politiken ofte kan 'snakke med' i de grupper og netværk, jeg færdes i, mens Information ikke gør det, så vil jeg være tilbøjelig til at finde Politiken mere 'worthwhile' end Information.

Den hollandske medieforsker Irene Costera Meijer har således fundet ud af, at for især unge mennesker handler nyhedsmedier mere om ‘kommunikation' end om ‘information': De bruger de 
nyhedsmedier, der bedst kobler dem på deres sociale netværk, ikke de nyhedsmedier der giver det største vidensudbytte (Meijer 2007).

\section{Normativt pres}

Det er altså sådan, at fællesskabets normer kan opleves af den enkelte som noget, der tilskynder positivt til brug af bestemte nyhedsmedier: Det vækker anerkendelse, hvis man kan sige, at man bruger et bestemt nyhedsmedie. Logisk set kan det også virke omvendt, dvs. et fællesskabs normative pres kan også tilskynde negativt til fravalg af bestemte nyhedsmedier, hvis den enkelte oplever, at der i et fællesskab er en misbilligelse af et nyhedsmedie. For eksempel husker mange sikkert, at der i gratisavisernes første periode, umiddelbart efter lanceringen i 2001, eksisterede en konsensus blandt intellektuelle og højtuddannede om, at gratisaviserne var for underlødige til at man skulle spilde sin tid på dem - de var dermed i en lang periode defineret som 'ikke worthwhile' i visse kredse. Et historisk eksempel på normativt pres findes i den næsten legendariske undskyldning om, at en information man har fra et billede- og sladderblad skyldes, at man har læst bladet 'hos frisøren'.

\section{Deltagerpotentiale}

En fjerde dimension i nyhedsmediers 'worthwhileness' har at gøre med deltagerpotentiale (participatory affordances), dvs. nyhedsmediets muligheder for, at man kan medvirke som aktiv deltager i nyhedstekstens videre liv i samfundet. Den trykte presse har gennem genren 'læserbrev' altid givet læserne mulighed for at ytre sig i spalterne, både for at fremsætte generelle kommentarer til sager på samfundets dagsorden, og for at respondere på og kritisere artikler bragt af avisen.

Med de interaktive medier har muligheden for at deltage i nyhedskredsløbet taget et kvantespring, som formentligt især appellerer til de yngre segmenter, der generelt har bedre digitale kompetencer end de ældre grupper. Picone (2007) har foretaget en systematisering af de interaktive muligheder i forbindelse med nyhedsformidling på nettet. Han skelner mellem 'tilbagelænede' og 'fremadlænede' muligheder for deltagelse, der begge 
kan udspille sig både i forhold til rollen som nyhedskonsument og rollen som bidragende nyhedsproducent.

Som nyhedskonsument kan man forholde sig 'tilbagelænet' og nøjes med at loese/lytte/se nyheder, men man kan også indtage en mere 'fremadlænet' position og søge bestemte nyhedsemner, eller abonnere på og få tilsendt historier inden for bestemte emner. Rollen som deltagende nyhedsproducent kan man indtage 'tilbagelænet' ved at emaile en journalists nyhedshistorie til en anden og 'tagge' en nyhedshistorie, eller 'fremadlænet' ved selv at levere 'bruger-genereret journalistik', fx ved at kommentere en nyhed på nyhedssitet eller selv levere (input til) en nyhedshistorie som borger-journalist.

\section{Pris}

Endelig er det nødvendigt at tage pris med på listen over dimensioner i 'worthwhileness', eftersom det helt kontant kan være prisen der forhindrer én i at abonnere på en avis eller tv-kanal, der ellers lever op til alle de øvrige betingelser for 'worthwhileness'. Et nyhedsmedie skal være prisen værd, og man skal have den økonomiske formåen til at betale den pris mediet koster.

\section{Mønstre af 'worthwhileness' i danskernes nyhedsbrug på tværs af medier}

Den undersøgelse af danskernes nyhedsbrug, som beskrives i det følgende, går ud fra den præmis, at det er af begrænset interesse at analysere folks brug af et enkelt nyhedsmedie, som fx TV-nyheder eller gratisaviser, set i isolation fra deres brug af de øvrige nyhedsmedier. Fordi folk sammensætter sig en 'nyhedsmediepakke', som de bevidst og ubevidst finder er deres tid og umage værd, indgår de til rådighed stående nyhedsmedier altså i et relationelt system, hvor valg og fravalg i sammensætningen af nyhedsmediepakken tilsammen sikrer opfyldelsen af de nyhedsbehov, som de enkelte har. Finnemann (2008) kalder dette relationelle system for en 'media matrix' og argumenterer:

"each medium has a set of distinct properties, while the specific role and use of any medium to some degree de- 
pends on the overall matrix of media available. You cannot analyse the role of any single medium independently of the overall matrix of media." (Finnemann 2008:7)

Undersøgelsen går altså ud fra, at den enkeltes brug af nyhedsmedier er styret af en selektionsmekanisme, der sikrer, at de valgte nyhedsmedier er 'worthwhile' og for tiden fungerer optimalt i den pågældendes hverdagssammenhæng, i forhold til de fem worthwhileness-dimensioner (tid, forbindelse til fællesskabet, normativt pres, deltagerpotentiale, og pris). I forlængelse af de generelle dimensioner i worthwhileness afhænger nyhedsmediebrugen også af specifikke faktorer, såsom hvilket niveau for nyhedsoverblik og/eller fordybelse og baggrund den enkelte vil opnå; hvilken grad af seriøs information og/eller underholdning den enkelte søger, osv. ${ }^{3}$

Forskningsprojektet består overordnet af to delundersøgelser: En (kvantitativ) survey-undersøgelse af danskernes nyhedsbrug på tværs af medier (gennemgås i det følgende), og en undersøgelse der gennem et kombineret kvantitativt og kvalitativt forskningsdesign (gennemføres i slutningen af 2009) søger at finde frem til en brugertypologi over nyhedsmediebrug i Danmark og på den måde at opnå en mere indgående forståelse af ikke blot at forskellige nyhedsmedier opleves som worthwhile, men hvordan og hvorfor det er tilfældet.

Survey-undersøgelsen kortlægger, hvilke danske nyhedsmedier der af danskerne opfattes som 'worthwhile' gennem en række forskellige vinkler på nyhedsbrugen, der tilsammen tegner et landkort over det danske nyhedsmarked set fra brugernes synsvinkel ultimo 2008. Undersøgelsen har værdi i sig selv som et snapshot af situationen anno 2008, men eftersom nyhedsmarkedet er i stadig forandring, i takt med at nye nyhedsmedier lanceres og folks nyhedsbehov og mediebrugsmønstre ændrer sig, vil det være af stor interesse at gentage undersøgelsen med jævne mellemrum for at fastslå, hvordan 'magtbalancen' mellem de forskellige nyhedsmedier ændrer sig over tid, og med hvilke sandsynlige konsekvenser for samfundsborgernes muligheder for at handle hensigtsmæssigt som politiske, økonomiske og kulturelle aktører. 
Survey-undersøgelsen foregik i oktober 2008 som et onlinespørgeskema, der blev besvaret af et panel af godt tusind danskere over 18 år. ${ }^{4}$ Spørgsmålene søgte at klarlægge tre overordnede spørgsmål:

- hvilke nyhedsmedier anser danskerne overhovedet for at være 'worthwhile?

- hvilke nyhedsmedier anser danskerne for at være mest ' worthwhile?

- hvilke nyhedsmedier anser danskerne for at være mest worthwhile inden for to forskellige nyhedsfunktionaliteter: skabelsen af et dagligt overblik over hvad der foregår omkring dem, og tilvejebringelsen af baggrundsviden om de ting, de finder vigtige.

Med hensyn til de to funktionaliteter skal det understreges, at vi undersøger folks oplevelse af de forskellige nyhedsmediers funktionalitet - vi har ikke på forhånd kategoriseret nyhedsmedierne som enten overbliks- eller baggrundsmedier. Folk kan således benytte sig af forskellige medier til at opfylde deres behov for overblik og baggrundsviden (fx radionyheder og morgenaviser), eller de kan opleve det sådan at samme medium kan tjene begge formål ( $\mathrm{fx}$ kan de opleve at TV-nyhedsudsendelser er leveringsdygtige i begge funktionaliteter).

\section{Hvilke nyhedsmedier oplever danskerne som worthwhile?}

Vi spurgte panelet, hvilke nyhedsmedier de havde brugt (læst/ hørt/set) i den sidste uge, og slutter os til, at hvis folk siger, at de har brugt et givet nyhedsmedium, så fortæller det os, at de finder dette medie 'worthwhile' (men ikke hvorfor de gør det - det undersøger vi i den opfølgende undersøgelse). Resultatet af denne analyse kan ses i Tabel $1 .^{5}$

Det er ikke så overraskende, at TV-nyheder på dansk er den nyhedstype, som flest danskere (88\%) - næsten alle de adspurgte har brugt i den seneste uge. Også Radionyheder har mange brugere (70\%). Så er det mere tankevækkende, at Nyheder på danske internetsider kommer ind på en meget klar andenplads (78\%), selvom manglen på tidligere undersøgelser betyder, at vi ikke 
kan sige noget om, hvornår netnyhederne har opnået denne position på det danske nyhedsmarked. Det har også overrasket os, at nyheder på det $\mathrm{i}$ andre undersøgelser oversete Tekst-tv kommer ind på en fjerdeplads, idet $60 \%$ finder dem worthwhile næsten $10 \%$ flere end dem der på syvendepladsen finder Landsdoekkende morgenaviser tiden, umagen og pengene værd. Vi hæfter os også ved, at ca. 20 \% siger, at de har brugt Nyheder på udenlandske internetsider og Nyheder på udenlandske tv-stationer. Det vil sige, at disse nyhedskilder må tages med i vurderingen af, hvordan danskerne tilvejebringer $\mathrm{fx}$ forudsætningerne for deres politiske stillingtagen.

De demografiske mønstre bag de nævnte tal er ikke i alle tilfælde statistisk signifikante, men kan give et fingerpeg om forskelle, der kan undersøges nærmere i fremtidig forskning. Således har Nyheder på nettet undervægt af aldersgruppen 56+, mens uddannelse ikke spiller en nævneværdig rolle, bortset fra at der er undervægt af gruppen, der kun har taget folkeskolen. Tekst- $t v$ har undervægt af brugere i aldersgruppen 56+ og blandt respondenter med kun folkeskole. Landsdcekkende morgenaviser læses af markant flere jo højere uddannelse, og jo højere alder.

Ser man på worthwhileness i forhold til brugernes alder, fremkommer der et interessant, om end ikke uventet mønster. Alle aldersgrupper nævner TV-nyheder som worthwhile. Den ældste gruppe 56+ læser aviser, både landsdækkende morgenaviser, lokale betalingsaviser og lokale gratis ugeaviser, de er betydeligt mindre tilbøjelige til at bruge Tekst-tv, og noget mindre tilbøjelige til at bruge netnyheder, især udenlandske. Den unge gruppe 18$\mathbf{1 5}$ er de mest hyppige brugere af netnyheder, og bruger ikke i særligt omfang trykte aviser. Den mellemste aldersgruppe ligner de yngre med hensyn til dagbladslæsning (lavt), danske netnyheder (højt) og Tekst-tv (højt), men de ligner de ældre mht. lokale ugeaviser (højt) og udenlandske netnyheder (lavt). 


\section{Tabel 1}

Danskernes top-16 over worthwhile nyhedsmedier, oktober 2008

Procent

\begin{tabular}{lc}
\hline $\begin{array}{l}\text { 1. Nyheder på dansk TV } \\
\text { (TV-Avisen, TV2 Nyhederne, TV2 News, DR Update) }\end{array}$ & 88 \\
\hline 2. Nyheder på danske internetsider & 78 \\
\hline 3. Nyhedsudsendelser i radioen & 70 \\
\hline 4. Nyheder på Tekst-TV & 60 \\
\hline 5. Lokale gratis ugeaviser & 5 \\
\hline 6. Aktualitetsmagasiner på dansk TV \\
\hline (fx Station 2, Kontant, Deadline, osv.) & 53 \\
\hline 7. Landsdækkende morgenaviser & 49 \\
\hline 8. Gratisaviser & 42 \\
\hline 9. Lokale/regionale dagblade & 36 \\
\hline 10. Fagblade & 31 \\
\hline 11. Magasiner og ugeblade & 30 \\
\hline 12. Formiddagsaviser & 27 \\
\hline 13. Nyheder udenlandske internetsider & 21 \\
\hline 14. Nyheds- og magasinprogrammer udenlandsk TV & 19 \\
\hline 15. Aktualitetsmagasiner radio & 14 \\
\hline 16. Mobiltelefon-nyheder & 7 \\
\hline Ingen af disse & 0 \\
\hline
\end{tabular}

$\mathrm{N}=1031$

Spørgsmål: Hvis du tænker tilbage på den seneste uge, hvilke af disse medietyper har du gjort brug af (set/hørt/læst osv.)?

\section{Hvilke nyhedsmedier oplever danskerne som mest worthwhile?}

I spørgeskemaets andet spørgsmål genererede online-designet til hver enkelt respondent en liste med de medier, som de netop havde nævnt som dem, de havde været i kontakt med, og spurgte „Hvilken af medietyperne ville du nødigst undvære?“ Svaret tolker vi således, at den valgte medietype er det nyhedsmedie, som respondenten anser for mest worthwhile. 


\section{Tabel 2}

Danskernes mest worthwhile nyhedsmedier (vil nødigst undvære), oktober 2008

\begin{tabular}{lc}
\hline TV Nyheder & $37 \%$ \\
\hline Danske internetnyheder & $19 \%$ \\
\hline Landsdækkende avis & $14 \%$ \\
\hline Radionyheder & $8 \%$ \\
\hline Tekst-TV-nyheder & $5 \%$ \\
\hline
\end{tabular}

$\mathrm{N}=1016$

Spørgsmål: Hvilken af medietyperne ville du nødigst undvære?

Igen er det ikke særligt overraskende, at nyhedsudsendelser på TV bliver topscorer, men samtidig viser tallene, at nettet er blevet et afgørende nyhedsmedie, mens den landsdækkende morgenavis kommer ind på en tredjeplads. Mange vil nok finde det overraskende, at hele $5 \%$ mener, at Nyheder på Tekst-TV er det mest uundværlige nyhedsmedie, mens det virker mere ventet, at radionyheder spiller denne rolle for $8 \%$ af danskerne. Gratisaviserne anses for uundværlig af så få $\left(1^{1} / 2 \%\right)$, at de ikke er med $\mathrm{i}$ Tabel 2.

Det hører med i billedet, at der er interessante demografiske forskelle på hvilket nyhedsmedie, danskerne anser for mest worthwhile: De højtuddannede føler sig markant mere knyttet til den landsdækkende morgenavis, og er den gruppe der helst vil undvære TV-nyheder. Netnyhederne er især uundværlige for gruppen 18-35 år, og vigtigheden aftager markant i grupperne 36 55 og $56+$. For den ældste gruppe $56+$ er vigtigheden af den landsdækkende avis lige så markant.

\section{Overblik versus baggrund: funktionaliteter i oplevet worthwhileness}

I en tidligere, kvalitativ undersøgelse af danskernes brug af informative medier (Phillips \& Schrøder 2004, Schrøder og Phillips 2007) viste det sig, at det var meningsfuldt at skelne analytisk mellem overbliks- og baggrundsmedier, og at det især var kortuddannede grupper der orienterede sig i retning af overbliksme- 


\section{Tabel 3}

Nyhedernes funktionaliteter: vigtigste overbliksmedie og vigtigste baggrundsmedie, oktober 2008

\begin{tabular}{lcc|cc}
\hline & \multicolumn{2}{c|}{ OVERBLIK } & \multicolumn{2}{c}{ BAGGRUND } \\
\hline & Ranking & $\%$ & Ranking & $\%$ \\
\hline Danske internetnyheder & 1 & $28 \%$ & 4 & $9 \%$ \\
\hline TV-nyheder & 2 & $27 \%$ & 2 & $24 \%$ \\
\hline Tekst-TV-nyheder & 3 & $15 \%$ & - & -- \\
\hline Radionyheder & 4 & $13 \%$ & - & -- \\
\hline Landsdækkende aviser & 5 & $6 \%$ & 1 & $28 \%$ \\
\hline Gratisaviser & 6 & $4 \%$ & & \\
\hline TV-aktualitet & -- & -- & 3 & $14 \%$ \\
\hline Lokal/regional dagblad & -- & --- & 5 & $4 \%$ \\
\hline
\end{tabular}

$\mathrm{N}=1016$

Spørgsmål: Her vil vi bede dig markere, hvilken medietype der er vigtigst for dig i to forskellige sammenhænge: Vælg venligst én medietype, som er vigtigst for dig, når du skal danne dig et "Nyhedsoverblik" (dvs. et dagligt overblik over, hvad der er sket af stort og småt). Og vælg venligst én medietype, som er vigtigst for dig, når du skal have „Baggrund og indsigt“" (dvs. baggrundsstof og fordybelse i, hvad der foregår i samfundet)?

dier, mens langtuddannede også havde behov for baggrundsnyhedsmedier.

I denne undersøgelse valgte vi at spørge eksplicit til folks opfattelse af, hvilke nyhedsmedier der er mest egnede til at levere overblik respektive baggrund/dybde. Vi spurgte med et kortlæggende snarere end et normativt sigte, idet vi antog, at alle mennesker opfatter sig selv sådan, at de har behov for både overblik og baggrund/dybde i deres brug af nyhedsmedier, og at det derfor ville være meningsfuldt at spørge til, hvilke medier de brugte til hvilket formål. 6

\section{Danskernes præferencer:}

\section{Overbliksmedie nr. 1 og baggrundsmedie nr. 1}

Resultaterne viser, at netnyheder (28\%) har opnået en position på niveau med TV-nyheder (27\%) som danskernes vigtigste overbliksmedie (Tabel 3). På de næste pladser, men langt bagefter, 
kommer Tekst-TV (15\%), der foretrækkes som overbliksmedie af flere end radio (13\%). Som de næste medier med tilslutning af betydning kommer landsdækkende aviser (6\%) og gratisaviser (4\%).

Den demografiske baggrund for disse tal tyder på, at netnyhedernes førsteplads er kendetegnet ved en overvægt af mænd og et aldersmønster der hedder jo yngre, jo vigtigere overbliksmedie. TV-nyheder og landsdækkende aviser bliver mere vigtige som overbliksmedie med alderen.

Som baggrundsmedier er landsdækkende aviser (28\%) og TVnyheder (24\%) i en kategori for sig. Med en høj placering i begge funktionaliteter viser TV sig i brugernes øjne som et virkeligt allround-nyhedsmedie, der leverer både overblik og baggrund i selve nyhedsudsendelserne, mens morgenaviserne udviser klar mono-funktionalitet som baggrundsmedie. TV-mediets styrke som leverandør af baggrund fremgår af, at TV-aktualitetsudsendelser indtager en klar tredjeplads (14\%), foran netnyhedsmedierne ( $9 \%)$.

\section{Danskernes præferencer:}

\section{Øvrige overbliksmedier og baggrundsmedier}

Når spørgeskemaet derefter giver folk mulighed for at vælge flere medietyper inden for hver funktionalitet (op til 3 i hver type), får vi stort set det samme billede, med enkelte variationer (Tabel 4): Inden for overbliksmedier er TV-Nyhederne tilbage på førstepladsen (55\%), med internetnyheder tæt efter (50\%). Så i det samlede billede, viser TV-nyheder sig altså at være det foretrukne overbliksmedie, mens netnyheder er gået i udbrud sammen med TV-nyheder, langt foran hovedfeltet af radionyheder (41\%) og Tekst-TV (36\%), og med Landsdækkende aviser (15\%) og Gratisaviser (13\%) nogle omgange bagefter.

Demografisk er TV-nyheders overbliksfunktion klart stigende med alderen, mens det for Netnyheder forholder sig omvendt. Også Tekst-TVs betydning som overbliksmedie falder klart med alderen. Gratisaviserne bruges nogenlunde ligeligt af de fire uddannelsesgrupper.

Også som baggrundsnyhedsmedie er TV dominerende (45\%), men på andenpladsen er det afløst af landsdækkende morgenaviser (36\%), der dog kører parløb med TV-Aktualitetsudsenden- 


\section{Tabel 4}

Nyhedsmediernes funktionaliteter: vigtigste øvrige overbliks- og baggrundsmedier, , oktober 2008

\begin{tabular}{lcc|cc}
\hline & \multicolumn{2}{c|}{ OVERBLIK } & \multicolumn{2}{c}{ BAGGRUND } \\
\hline & 1 & $55 \%$ & 1 & $45 \%$ \\
\hline TV nyheder & 2 & $50 \%$ & 4 & $24 \%$ \\
\hline Dansk netnyheder & 3 & $41 \%$ & 6 & $13 \%$ \\
\hline Radionyheder & 4 & $36 \%$ & --- & -- \\
\hline Tekst-TV & 5 & $15 \%$ & 2 & $36 \%$ \\
\hline Landsdækkende aviser & 6 & $13 \%$ & -- & -- \\
\hline Gratisaviser & -- & -- & 3 & $35 \%$ \\
\hline TV-aktualitet & -- & -- & 5 & $13 \%$ \\
\hline Fagblade & 7 & $10 \%$ & 7 & $11 \%$ \\
\hline Lokale/regionale dagbl. & -- & -- & 8 & $10 \%$ \\
\hline Radio-aktualitet & 8 & $9 \%$ & 9 & $7 \%$ \\
\hline Lokale gratis ugeaviser & & & & \\
\hline
\end{tabular}

\section{$\mathrm{N}=1016$}

Spørgsmål: Her vil vi bede dig markere, hvilke andre medietyper der er vigtige for dig igen i to forskellige sammenhænge: Vælg venligst op til 3 medietyper, som er vigtige for dig, når du skal danne dig et "Nyhedsoverblik“ (dvs. et dagligt overblik over, hvad der er sket af stort og småt). $0 \mathrm{~g}$ vælg venligst op til 3 medietyper, som er vigtige for dig, når du skal have „Baggrund og indsigt“ (dvs. baggrundsstof og fordybelse i, hvad der foregår i samfundet)?

ser (35\%), med god afstand ned til Netnyhederne (24\%). Herfra er der så igen et kraftigt spring ned til Fagblade (13\%) der ligger lige med Radionyheder (13\%) som baggrunds-leverandør.

Blandt de vigtigste demografiske tendenser for baggrundmedier finder vi, at det især er lavtuddannede der bruger TV-Nyheder til at skaffe sig baggrund, mens de højtuddannede og ældre grupper er orienteret imod betalingsaviserne. For den unge aldersgruppe er internetnyheder en vigtigere kilde til baggrundviden end landsdækkende aviser. Fagblade og Radioaktualitetsprogrammer (DR-P1-fladen) er især vigtige for gruppen 56+ og for de højtuddannede.

Konkluderende kan det siges, at danskernes eneste absolutte 
allround-nyhedsmedie anno 2008 således er TV-nyheder (to klare førstepladser), en rolle som de landsdækkende aviser klart har mistet (en 5. og en 2. plads), mens internetnyheder er på vej til at gøre TV-nyheder rangen stridig (en 2. og en 4. plads). Uden for København spiller de landsækkende dagblade en lidt mindre rolle, mens til gengæld de regionale og lokale dagblade spiller en større rolle i nyhedsbilledet, både som overbliks- og baggrundmedier.

Alle andre nyhedsmedier end TV-nyheder og internetnyheder er kendetegnet ved en klar funktionsopdeling (monofunktionalitet), således at radionyheder, tekst-tv og gratisaviser er rene overbliksmedier, mens landsækkende og regionale aviser, TV-Aktualitetsprogrammer og Fagblade er baggrundsmedier.

\section{Oplevelsen af gratisavisernes kvaliteter}

Der eksisterer en del viden om gratisavisernes læsere i andre lande, som er baseret på oplags- og læsertalsmålinger (Bakker 2007; Wadbring 2007). Fra sådanne undersøgelser ved man, hvordan de forskellige titler klarer sig markedsmæssigt i den indbyrdes konkurrence, og i konkurrencen med betalingsaviserne. Det er ligeledes kendt, at gratisaviserne (i hvert fald i Sverige, jf. Wadbring 2007) ikke er årsagen til betalingsavisernes problemer, men at de snarere fungerer som et supplement til de eksisterende aviser end som en gøgeunge, der skubber betalingsaviserne ud af nyhedsmarkedet. Endvidere har Wadbring påvist, at det især er for ressourcesvage grupper (fx indvandrere) og unge mennesker, at gratisaviserne fungerer som eneste trykte avis, og dermed som en vigtig ressource for 'forbindelse til fællesskabet', såvel i demokratisk som i mere hverdagslig forstand.

I denne undersøgelse blev der fokuseret på respondenternes oplevelse af forskellige kvaliteter ved gratisaviserne, der på undersøgelsestidspunktet omfattede 3 titler: de to titler fra første gratisavisbølge i 2001 (metroXpress og Urban) og den eneste overlevende titel fra anden bølge i 2006 (24timer).

Vi spurgte om tre ting: 1. Hvor gode eller dårlige synes du gratisaviserne (metroXpress, Urban, 24timer) generelt er som nyhedssmedier? 2. Hvor gode eller dårlige synes du gratisaviserne 
(metroXpress, Urban, 24timer) er til at give et overblik over dagens nyheder? 3. Hvor gode eller dårlige synes du gratisaviserne (metroXpress, Urban, 24timer) er til at give baggrund for og indsigt i dagens nyheder? I alle tre tilfælde skulle respondenterne vurdere gratisavisernes placering på en glidende skala fra 1 til 10.

Hvad angår gratisavisernes generelle kvalitet som nyhedsmedier vurderer respondenterne dem som 5 ud af 10, altså middelgode. Folk med høj uddannelse vurderer dem lidt lavere $(4,5)$ end de tre øvrige uddannelsesgrupper $(5,2)$.

Svarene på spørgsmålene om nyhedernes funktionalitet viser ikke overraskende, at gratisavisernes styrke ligger i overbliksfunktionen (5,8 ud af 10), mens baggrundsfunktionen vurderes lavere $(4,3)$. Det bekræfter gratisavisernes vigtige rolle i befolkningsgrupper med kort uddannelse, at disse vurderer gratisaviserne højere som leverandører af baggrund. Tilsvarende værdsættes den overblikskabende funktion proportionalt med alder, fra 6,4 blandt de 18-35-årige, til 5,5 blandt gruppen 56+. Nedenfor sammenlignes gratisaviserne med de øvrige nyhedsmedier med hensyn til troværdighed og informativitet.

\section{Er nyhedsmedierne informative eller underholdende?}

Det har i snart mange år været opfattelsen i kulturkritiske kredse, at mediekulturen er ved at drukne os i underholdning. I den internationale kultur- og medieforskning går opfattelsen mindst tilbage til kritikken af boulevardpressen i det 19. århundrede, mens den fik sit autoritative teoretiske fundament i 1940erne med Frankfurterskolens analyser af 'kulturindustrien', der forfører masserne med fascinerende men næringsfattig underholdning i stedet for at levere sober information, der tilskynder borgerne til rationel, politisk stillingtagen. Opfattelsen er blevet regelmæssigt holdt ved lige gennem årene, fx af amerikaneren Neil Postman, der i 1980erne argumenterede for at medierne er skyld i at vi „morer os til døde“ og at „seriøst tv“ er en selvmodsigelse (Postman 1985). Her et eksempel fra en dansk sammenhæng:

„TV har svigtet folkeoplysningen, kulturen og sproget til fordel for perspektivløs dansk og udenlandsk underhold- 
ning. (...) Efter min mening repræsenterer 1996 på begge stationer det kulturelle nulpunkt, det punkt, hvorefter de skadelige virkninger på kulturen er større end de gavnlige“ (Lund 1997)

Der er næppe tvivl om, at der i dag er mere medieindhold af den underholdende type i det offentlige rum, end der var for år tilbage. Samtidig har der været bevægelse i opfattelserne af, hvad det vil sige at noget er underholdende, og om det underholdende nødvendigvis er det oplysendes modstander (Van Zoonen 2005).

I bogen Restyling Factual Television (2007) undersøger Annette Hill, hvordan engelske og svenske mediebrugere i bred forstand opfatter forskellige tv-genrer, der i en eller anden, non-fiktiv, forstand beretter om virkeligheden (faktuelle genrer) i spændingsfeltet mellem det informative og det underholdende. Hun finder, at der er nogle få faktuelle tv-genrer, der opleves relativt entydigt som informative (TV-nyheder) eller underholdende ('reality'genrer), mens de fleste genrer opleves som en blanding af det informative og det underholdende ( $\mathrm{fx}$ forbrugerprogrammer, rekonstruktionsprogrammer, livsstilsprogrammer (Hill 2007:74)).

I forlængelse heraf besluttede vi at spørge vores panel om det samme i forhold til den brede palet af 14 nyhedsgenrer, som indgik i vores undersøgelse. Ved at spørge til nyhedsmediernes informations- og underholdningsværdi, og deres troværdighed (se nedenfor), tager vi hul på den undersøgelse af, hvad der indholdsmæssigt ligger i worthwhileness, som primært finder sted i projektets næste fase.

Respondenterne svarede ved at trække en blå kugle med musen til den ønskede position på en skala fra 1 (mest underholdende) til 10 (mest informativ). Resultatet kan ses i Tabel 5. ${ }^{7}$ Med én undtagelse anser borgerne alle danske nyhedsmedier for at være mere informative end underholdende. Kun formiddagsaviserne Ekstra Bladet og BT anses (med scoren 3,7) for at være betydeligt mere underholdende end informative.

Ingen danske nyhedsmedier anses for at være rent informative. Selv de mest informative nyhedsmedier opfattes som $20-25 \%$ underholdende. Fire nyhedsmedier er i en klasse for sig mht. informationsværdi: Radionyheder, TV-nyheder, morgenaviser og 


\section{Tabel 5}

Vurdering af danske nyhedsmedier mellem information og underholdning (skala 010), oktober 2008

Skala 0-10

\begin{tabular}{ll}
\hline 1. Radionyheder & 7,7 \\
\hline 2. TV-nyheder & 7,7 \\
\hline 3. Landsdækkende avis & 7,6 \\
\hline 4. Tekst-TV & 7,6 \\
\hline 5. Internet-nyheder danske & 6,9 \\
\hline 6. Radioaktualitet & 6,6 \\
\hline 7. TV-nyheder internationalt & 6,6 \\
\hline 8. TV-aktualitet & 6,5 \\
\hline 9. Lokale dagblade & 6,4 \\
\hline 10. Internet internationale & 6,2 \\
\hline 11. Gratisaviser & 5,1 \\
\hline 12. Lokale ugeaviser & 5,0 \\
\hline 13. Mobiltelefon & 4,9 \\
\hline 14. Formiddagsaviser & 3,7 \\
\hline
\end{tabular}

$\mathrm{N}=1016$

Spørgsmål: Nyhedsmedier kan være mere eller mindre informative og/eller underholdende. I det følgende vil vi bede dig vurdere 14 forskellige medietyper og angive, om du opfatter den enkelte medietype som informativ eller underholdende. Opfatter du nedenstående medietype som informativ eller underholdende? Træk den blå kugle mod det ønskede svar.

Tekst-TV. Det er der enighed om på tværs af køn, uddannelse og klasse.

I en mellemgruppe med klart informativ profil finder vi danske netnyheder, radio og TVs aktualitetsudsendelser (en meget bred kategori, der indeholder programmer som Basta, Kontant, Profilen, Station 2, Deadline, osv.), lokale dagblade og internationale nyhedstjenester på TV og på nettet.

I den lave ende finder vi gratisaviser, lokale ugeaviser og mobilnyheder, med en oplevet balance mellem underholdning og information. Lavest ligger som nævnt formiddagsaviserne. 


\section{Hvor troværdige opleves nyhedsmedierne at være?}

Troværdighedsmålinger er formentlig én af de hyppigst gennemførte målinger af, hvordan folk oplever nyhedsmedierne (se fx Lund 2001; for en undersøgelse foretaget i 2008 af magasinet Limited Edition: se http://www.business.dk/article/20080505/medier/80505076/). Vores resultater (Tabel 6) afviger ikke fra det mønster, man plejer at finde i sådanne målinger.

Danskerne anser hovedparten af de nyhedsmedier, de anvender mest, for at have en meget høj troværdighed. Det er nyhederne fra de to public service-kanaler og de store morgenaviser, der nyder denne tillid. Men vurderingen viser samtidig, at danskerne anser det for nødvendigt at omgås selv de mest troværdige nyhedsmedier med et vist kritisk beredskab - muligheden for, at det man får at vide er forkert, er altid til stede.

En stor mellemgruppe af nyhedsmedier, der stort set produceres af de samme mediehuse som topscorerne, ligger ret tæt mht. troværdighed: Tekst-TV, aktualitetsudsendelser i radio og TV, danske netnyheder, lokale dagblade, og internationale TV-nyheder. Herunder finder vi en gruppe med internationale netnyheder, lokale ugeaviser, gratisaviser og mobilnyheder, mens formiddagsaviserne igen ligger helt i bund, og læses formentlig mest for deres underholdningsværdi. De, der læser dem (Uddannelsesgruppe 1), anser dem dog for at være mere troværdige end dem der ikke læser dem.

Det er slående, om end ikke overraskende, at troværdighedsopfattelsen meget nøje følger opfattelsen af informativitet og underholdning. Hvis man sammenligner ranglisterne for de to målinger (Tabel 5 og 6) er der i fire tilfælde tale om den eksakt samme placering, i seks tilfælde tale om en divergens på 1 plads, og i de resterende seks tilfælde en divergens på 2 pladser. Blandt de 5 øverst placerede på begge lister er der højst én plads til forskel. 


\section{Tabel 6}

Vurdering af danske nyhedsmediernes troværdighed (skala 0-10), oktober 2008

\begin{tabular}{lcc}
\hline & & Placering mht. underholdning (jf. Tabel 5) \\
\hline 1. TV-nyheder & 7,9 & 2. \\
\hline 2. Radionyheder & 7,8 & 1. \\
\hline 3. Landsdækkende avis & 7,8 & 3. \\
\hline 4. Tekst-TV & 7,3 & 4. \\
\hline 5. Radioaktualitet & 7,3 & 6. \\
\hline 6. TV-aktualitet & 7,2 & 8. \\
\hline 7. Internet-nyheder danske & 6,9 & 5. \\
\hline 8. Lokale dagblade & 6,7 & 9. \\
\hline 9. TV-nyheder internat. & 6,5 & 7. \\
\hline 10. Internet internationale & 5,8 & 10. \\
\hline 11. Lokale ugeaviser & 5,5 & 12. \\
\hline 12. Gratisaviser & 5,4 & 11. \\
\hline 13. Mobiltelefon & 5,0 & 13. \\
\hline 14. Formiddagsaviser & 3,9 & 14. \\
\hline
\end{tabular}

$\mathrm{N}=1016$

I det følgende vil vi bede dig vurdere de samme 14 medietyper og angive, hvor troværdig eller utroværdig den enkelte medietype er. Hvor troværdig eller utroværdig er nedenstående medietype? Træk den blå kugle mod det ønskede svar.

\section{Netnyhedsmedier: Hvor interaktive er folk på nyheds-sites?}

Det siges ofte, at det tiltrækkende ved nyheder på internettet er de interaktive muligheder: Man kan deltage i debatter, lægge en kommentar på en blog, sende en email til en journalist, sende et nyhedstip til en ven, osv. (Picone 2007). Eksisterende undersøgelser tyder dog på, at det stadig er et mindretal, der faktisk er interaktive på nettet som producenter af indhold (Gentikow 2008). Vores respondenters svar på spørgsmålet om, hvilke former for interaktivitet de har deltaget i inden for den sidste måned, bekræfter dette indtryk (Tabel 7).

Hele $76 \%$ svarer, at de ikke har benyttet sig af de interaktive 


\section{Tabel 7}

Brugernes angivelse af benyttede interaktivitetstyper på nyheds-sites den seneste måned (\%), oktober 2008

\begin{tabular}{lc}
\hline & Procent \\
\hline 1. Ingen interaktivitet & $76 \%$ \\
\hline 2. Deltaget i en debat & $11 \%$ \\
\hline 3. Kommenteret en artikel & $9 \%$ \\
\hline 4. Sendt en email til en journalist & $7 \%$ \\
\hline 5. Kommenteret en blog & $6 \%$ \\
\hline 6. Skrevet et blog-indlæg & $5 \%$ \\
\hline 7. Sendt en sms med et nyhedstip & $4 \%$ \\
\hline
\end{tabular}

$\mathrm{N}=1031$

Spørgsmål: De fleste internet nyheds-websteder giver mulighed for at kommentere artikler, for at kommentere blogs, for at deltage i debat, og for selv at levere nyheder tilmediet. Hvilke af disse muligheder - om nogen - har du gjort brug af inden for den seneste måned?

muligheder. De 24\%, der har været interaktive, har især benyttet sig af hvad man kan kalde 'reaktive' former for interaktivitet, dvs. at de 'svarer på' et journalistisk input, som en anden (journalist eller blog-ejer) har udsendt, eller deltager i en debat, som andre har startet.

Svarene på et andet spørgsmål om, hvor vigtige respondenterne anser de interaktive muligheder for at være, bekræfter indtrykket at, at de fleste er ret ligeglade med nyheds-sitenes interaktive muligheder (den gennemsnitlige vurdering af vigtigheden er 3,3 af 10).

\section{Perspektivering af undersøgelsen}

Det vil være oplagt at følge survey-undersøgelsen op på to måder: For det første ved at gentage den med et eller flere års mellemrum for at justere landkortet over nyhedsmediebrug i takt med at borger-forbrugernes navigation på nyhedsområdet forandrer sig. For det andet ved at supplere survey-undersøgelserne med kvalitative undersøgelse af, hvordan borger-forbrugerne oplever de 
forskellige nyhedsmediers konkrete worthwhileness i hverdagen: indhold, rutiner, osv. En sådan undersøgelse er igangsat.

Som det er fremgået af de enkelte analyser ovenfor, så er det klart, at et af bjergene i dagens nyhedslandskab er nyheder på nettet. For at blive i metaforen kan man sige, at der her er tale om et hastigt voksende vulkansk bjerg, der er i konstant udbrud og truer med at begrave de øvrige nyhedsmedier i hastigt tempo.

Det er vigtigt at reflektere over, hvad det betyder for nyhedskulturen, og ikke mindst for vores opfattelse af folks forhold til nyhedsmedier, at en nyhedskultur domineret af TV er ved at blive fortrængt af en nyhedskultur domineret af netnyheder. Curran m. fl (2009), der vurderer nyhedsmediernes demokratiske rolle uden at inddrage netnyheder, bidrager til at forstærke den myte, at mange borgere-forbrugere er modvillige nyhedsbrugere, der skal lokkes til at se nyheder på tv:

“(The public service model has a greater ability) to engage an 'inadvertent' audience: people who might be generally disinclined to follow the course of public affairs, but who cannot help encountering news while awaiting delivery of their favourite entertainment programmes. The fact that public service television intersperses news with entertainment increases the size of the inadvertent audience." (Curran m.fl. 2009:22)

Ganske vist viser vores undersøgelse, at TV-nyheder stadig er et dominerende allround nyhedsmedie i Danmark. Men samtidig er det klart, at $78 \%$ af forbruger-borgerne bruger nyheder på nettet (Tabel 1), at 19\% oplever danske netnyheder som 'mest worthwhile' (Tabel 2), at flere anser netnyheder (28\%) for at være lige så vigtigt som overbliksmedie som TV-nyheder $27 \%$ (Tabel 3), og at $50 \%$ anser netnyheder for at være gode til at skaffe sig et overblik (Tabel 4).

I og med at netnyheder er et medie man aktivt opsøger, er der således noget der tyder på, at vores resultater om nyhedsbrug ud over det helt nye kort over det samlede nyhedslandskab - også kan gøre op med den opfattelse, at folk er vrangvillige brugere af nyheder. Når man ser TV-nyheder, vil det ofte være sådan, at man 
'flyder med nyhedsstrømmen', som andre har valgt for én. Jo mere internettet vinder frem som nyhedsmedie, jo tydeligere bliver det, at folk selv sammensætter deres nyhedsmenu på en sådan måde, at det, de fortærer, er worthwhile og sikrer deres 'forbindelse til fællesskabet'.

\section{NOTER}

1. Undersøgelsen indgår i projektet Aviser og journalistik i forandring, der har modtaget støtte fra Forskningsrådet for Kultur og Kommunikation og består af i alt 7 delprojekter. Se http://aviser.mef.ku.dk/. Undersøgelsen har derfor på mange måder nydt godt af inspiration of feedback fra projektets deltagere: Henrik Bødker, Camilla Dindler, Unni From, Stig Hjarvard, Nete Nørgaard Kristensen, og Ida Willig. Surveyen er gennemført i samarbejde med Politikens analyseafdeling.

2. Anvendelsen af begreber som 'behov', 'brug' og 'pay-off' i artiklens indledning leder måske nogle læseres tanker i retning af uses-andgratifications-traditionen (Blumler \& Katz 1974). Der er også berøringspunkter mellem visse af worthwhileness-dimensionerne og $\mathrm{fx}$ Lull's (1980) U+G-inspirerede 'uses of television'. Men på andre måder er undersøgelsen ikke en U+G-undersøgelse - fordi den grundlæggende ikke anser individers valg af nyhedsmedier for at være styret af en bestræbelse på rationel behovsopfyldelse, men snarere af en Giddensk 'practical consciousness' (Giddens 1984), der er indlejret i rutiner i sociale fællesskaber. Desuden tilhører dimensionerne i worthwhileness ikke, som i U+G-forskningen, en universel liste over mulige nyheds-'gratifications', men er en række kontekstspecifikke hensyn, som hver især og tilsammen indgår i individers bevidste og ubevidste, rutiniserede kalkule over valg og brug af nyhedsmedier. For en diskussion af receptionsforskningens forhold til U+G-forskningen, se Schrøder 1999.

3. Worthwhileness-begrebet er ikke færdigudviklet. Ud over de nævnte fem sideordnede dimensioner er det muligt, at der skal tilføjes flerefor eksempel er det måske hensigtsmæssigt at tænke indholdskarakteristika som underholdning, informativitet og troværdighed som dimensioner, der indgår i worthwhileness. Det er også muligt, at 
worthwhileness-dimensionerne med fordel kan grupperes i fx formåls-, indholds-, situations- og teknologiske kategorier. Jeg takker en af Journalisticas anonyme fagfællebedømmere for inspiration til at videreudvikle worthwhilenessbegrebet i disse retninger.

4. Spørgeskemaundersøgelsen er gennemført af analysefirmaet WebPol i samarbejde med Bent Steeg Larsen og Poul Melbye fra Politikens analyseafdeling. Den omfatter bl.a. de tre demografiske variable køn, uddannelse og alder. Uddannelse omfatter 4 grupper: Folkeskole op til 10. klasse, ungdomsuddannelse (studentereksamen), kort videregående uddannelse, og lang videregående uddannelse. Alder omfatter 3 grupper: 18-35 år, 36-55 år, og 56+.

5. Forskellen mellem svarkategoriernes andele i Tabel 1, 2, 3, 4 og 7 er statistisk signifikante på 95\%-niveau, bortset fra de tilfælde hvor forskellen er mindre end 3-4 procentpoint. Her kunne rækkefølgen mellem to medietyper være den omvendte.

6. Betegnelsen 'overblik' indeholder i hvert fald to behovs- og oplevelsesdimensioner, som der måske bør skelnes imellem i fremtidige undersøgelser: På den ene side kan der være tale om, at en person søger en sammenfatning af hvad der er sket i et forudgående tidsrum, fx når man om aftenen har brug for en sammenfatning af dagens vigtigste begivenheder. På den anden side kan der være tale om, at en person søger en kontinuerlig opdatering af hvad der sker, fx hvordan en bestemt sag udvikler sig gennem dagen. I denne undersøgelse må vi regne med, at respondenternes forhandling af 'overblik' resulterer i svar, der rapporterer om enten sammenfatning eller opdatering, eller en blanding af disse. Tak til Stig Hjarvard for denne præcisering.

7. Forskellene mellem nyhedsmediernes gennemsnitlige informationsværdi (Tabel 5) og troværdighed (Tabel 6) er statistisk signifikant på 95\%-niveau, bortset fra de tilfælde, hvor forskellen er 0,1 eller derunder. Her kunne rækkefølgen mellem to medietyper være den omvendte. Hvor der sker interessante ryk i opfattelsen, er dette markeret med horisontal understregning.

\section{REFEREN C ER}

Bakker, Piet (2007) "The impact of free daily newspapers on the circulation of paid newspapers", Paper presented to the ICA Conference, San Francisco, May 24-28. 
Beeftink, Belinda (2009). TouchPoints - The First Three Years. Præsentation i DRs Koncerthus 11.11.2009. http://www.m ultimediamennesket.dk/m3 praesentation bb_111109.pdf (16.12.2009)

Berelson, Bernard (1949), "What 'missing the newspaper' means”, I Lazarsfeld, P.E. \& Stanton, F.N. (red.), Communication Research 1948-49, New York: Harper \& Brothers.

Blumler, Jay G. \& Katz, Elihu (1974) (red.), The Uses of Mass Communications, Beverly Hills: Sage.

Bourdieu, Pierre (1998), Om TV-og journalistikkens magt, København: Tiderne Skifter.

Bødker, Henrik. (2007). „Politik som trykte liv“. Journalistica 2007, nr. 5. Couldry, Nick, Livingstone, Sonia, Markham, Tim (2007), Media Consumption and Public Engagement. Beyond the Presumption of Attention, Basingstoke: Palgrave macmillan.

Curran, James; Lund, Anker Brink; Iyengar, Shanto and Inka SalovaaraMoring (2009), "Media system, public knowledge and democracy: A comparative study”, European Journal of Communication, 24:5, 5-26.

Dahlgren, Peter (2001), “The public sphere and the net: structure, space and communication”, I W. Lance Bennett \& R.M. Entmann (red.), Mediated Politics: Communication in the Future of Democracy. Cambridge: Cambridge University Press, 33-55.

Dahlgren, Peter (2006), "Doing citizenship: The cultural origins of civic agency in the public sphere", European Journal of Cultural Studies, 9(3), 267-286.

Delli Carpini, Michael X. \& Williams, Bruce A. (2001), "Let Us Infotain You: Politics in the New Media Environment”, I Lance W. Bennett \& Robert M. Entman, red., Mediated Politics: Communication in the Future of Democracy. Cambridge: Cambridge University Press.

Eide, Martin. (1992). „Den fjerde servicemakt. Noter til forståelse av norsk veilednings- og kampanjejournalistik“. Arbejdspapir. Institutt for massekommunikasjon, Universitetet i Bergen.

Finnemann, Niels O. (2008) “The Internet and the Emergence of a New Matrix of Media.". Paper presented to the Association of Internet Researchers Conference, Copenhagen, October 2008.

Gentikow, Barbara (2008). „Mediepublikumet i en brytningstid: Revitaliseringer og transformasjoner“. Norsk medietidsskrift, 15, 2:84-104.

Giddens, Anthony (1984), The Constitution of Society, Cambridge: Polity Press. 
Habermas, Jürgen (1962), Strukturwandel der Öffentlichkeit, Darmstadt \& Neuwied, Germany: Hermann Luchterhand Verlag.

Habermas, Jürgen (2006), "Political communication in the media society: Does democracy still enjoy an epistemic dimension? The impact of normative theory on empirical research", Communication Theory, 16: 411-426.

Hill, Annette (2007) Restyling Factual TV. Audiences and News, Documentary and Reality Genres. London: Routledge.

Hjarvard, Stig (1999) TV-Nyheder I konkurrence, København: Samfundslitteratur.

Jones, Jeffrey P. (2006), "A cultural approach to the study of mediated citizenship", Social Semiotics, 16(2), 365-383.

Kabel, Lars (2009) (red.), Nyheder i nutid, Århus: Ajour/Update.

Kromann-Larsen (2009). TNS Gallup: MultiMediaMennesket. Præsentation i DRs Koncerthus 11.11.2009. http://www. multimediamennesket.dk/m3 praesentation mkl 111109.pdf (16.12.2009)

Lull, James (1980). “The social uses of television”. Human Communication Research 6, 197-209.

Lund, Anker Brink (2000), Først med det sidste - en nyhedsuge I Danmark, Århus: Ajour.

Lund, Anker Brink (2001), Forskning om medier og demokrati, Danske Dagblades Forening.

Lund, Anker Brink (2002), Den redigerende magt. Nyhedsinstitutionens politiske indflydelse, Århus: Århus Universitetspresse.

Lund, Anker Brink, Ida Willig og Mark Blach-Ørsten (2009). Hvor kommer nyhederne fra? Den journalistiske fødekcede i Danmark før og $n u$. Aarhus: Forlaget Ajour.

Lund, Jørn (1997). „Det kulturelle nulpunkt“. Kronik i Politiken, 29. august 1997.

McNair, Brian (2006), Cultural Chaos: Journalism, News and Power in a globalised world, London: Routledge.

Meijer, Irene Costera (2007). “Checking, snacking and bodysnatching. How young people use the news and implications for public service media journalism”. In: Lowe, G.F. \& Bardoel, J. (eds.). From Public Service Broadcasting to Public Service Media. Gothenburg: Nordicom.

Phillips, Louise and Schrøder, Kim Christian (2004), Sådan taler medier og borgere om politik. En diskursanalytisk undersøgelse afpolitik $i$ det medialiserede samfund, Aarhus: Aarhus University Press. 
Picone, I. (2007). “Conceptualising online news use”. Observatorio, 3, 93114.

Postman, Neil (1985). Amusing Ourselves to Death. Public Discourse in the Age of Show Business. London: Methuen.

Poulsen, Jørgen (1998). Måske-laeserne. Dagbladenes muligheder $i$ mediekonkurrencen. Hovedrapport fra projektet „Måske-læserne“, Institut for Kommunikation, Roskilde Universitet.

Schrøder, Kim Christian (1999). "The best of both worlds? Media audience research between rival paradigms”. In Pertti Alasuutari (red.). Rethinking the Media Audience. The New Agenda. London: Sage, 3868.

Schrøder. Kim Christian \& Phillips, Louise (2007), "Complexifying media power: A study of the interplay between media and audience discourses on politics", Media, Culture \& Society 29(5).

TNS Gallup (2009). Multimediamennesket. http://www.tns-gallup.dk/ vores-markedsfokus/medier/multi-media-mennesket.aspx $\quad$ (16.12. 2009)

Wadbring, Ingela (2007), „Konsekvenser af daglige gratistidningar på marknaden - svenske erfarenheter“, MedieKultur 42/43, 86-101.

Zoonen, Liesbet Van (2005). Entertaining the Citizen: When Politics and Popular Culture Converge. Lanham, MD: Rowman and Littlefield. 


\section{English Abstracts}

\section{News consumers' navigation in the cross-media news landscape: Towards a new map of news consumption \\ KIM SCHRØDER}

The article offers new insights by mapping the use and users of today's news media landscape, as the everyday consumption of news across the range of available news media and formats is shifting as a result of transformations of media technologies, cultures and lifestyles. Theoretically the study is anchored in Habermas's notion of the public sphere, and its recent reconceptualizations in theories of 'cultural citizenship', 'civic agency' and 'public connection' (Dahlgren 2006; Couldry, Livingstone \& Markham 2007). The project operationalizes these theories through the concept of users' perceived worthwhileness of news media, a concept which incorporates the different functionalities of the crossmedia consumption of news by citizen/consumers in everyday life. Empirically the paper presents the findings of a large-scale online survey (October 2008) that maps aspects of the citizenconsumers' navigation in the contemporary Danish news media landscape, as a consequence of accelerating divisions between 'overview' and 'depth' news media (across print, broadcasting and the internet). The article also reports on specific findings about the use of free dailies, the credibility of various news sources, and the interactivity of news publics. 